\title{
LA CONCESIÓN DE VENTA Y LA COMPETENCIA JUDICIAL INTERNACIONAL
}

\author{
DISTRIBUTION OF GOODS AND INTERNATIONAL JURISDICTION
}

\author{
María Asunción Cebrián Salvat \\ Universidad de Murcia. España/Spain \\ masuncion.cebrian@um.es
}

Recibido/Received: 21/01/2015

Aceptado/Accepted: 27/04/2015

\section{RESUMEN}

La cuestión de la calificación de los distintos tipos de contratos de distribución a efectos del art. 5.1 del Reglamento Bruselas I bis (actual art. 7.1 Reglamento Bruselas I bis) ha sido muy controvertida en los últimos años tanto jurisprudencial como doctrinalmente. El presente artículo, después de analizar las posiciones existentes en relación con esta cuestión, defiende la postura que ha adoptado recientemente el Tribunal de Justicia de la Unión Europea respecto a un contrato de concesión de venta, esto es, la calificación de los contratos de distribución como contratos de prestación de servicios a cargo del distribuidor.

\section{PALABRAS CLAVE}

Contratos de concesión de venta, contratos de distribución, compraventa de mercaderías, prestación de servicios, competencia judicial internacional en materia contractual.

\section{SUMARIO}

I. Contratos de concesión de venta y contratos de distribución en la Unión Europea. II. Competencia judicial internacional en defecto de pacto y contratos de distribución en el Reglamento Bruselas I bis. III. El contrato de concesión de venta en el art. 7.1 Reglamento Bruselas I bis: nuevas reflexiones a partir de la STJUE Corman-Collins v. La Maison du Whisky. IV. Consideraciones finales. Bibliografía.

\begin{abstract}
The characterization of the different kinds of distribution contracts under art. 5.1 Brussels I Regulation (current art. 7.1 Brussels I Regulation Recast) is a controversial issue. This paper analyzes the different doctrinal and jurisprudential positions in relation to this subject and defends the opinion of the European Court of Justice regarding these contracts, this is, that they should be considered as a provision of services delivered by the distributor.
\end{abstract}

\section{KEYWORDS}

Distribution of goods, distributorship agreements, sale of goods, provision of services, international jurisdiction in matters relating to contract.

\section{CONTENTS}

I. The distribution of goods in the European Union. II. International jurisdiction in the absence of a jurisdiction clause and distribution contracts in the Brussels I Regulation (recast). III. The distribution contract in art. 7.1 Brussels I Regulation (recast): new thoughts from the STJUE Corman-Collins v. La Maison du Whisky. IV. Final considerations. References. 


\section{CONTRATOS DE CONCESIÓN DE VENTA Y CONTRATOS DE DISTRIBUCIÓN EN LA UNIÓN EUROPEA}

En la categoría jurídica de los contratos de distribución comercial existe una patente confusión terminológica. Mirosa Martínez se refiere a este fenómeno como el "bailoteo semántico organizado por unos y otros en el ámbito de las redes de comercialización" (Mirosa Martínez, 2009:16). En el centro de toda esta confusión está la diversa y enfrentada utilización de los términos "distribución", "concesión", y de los adjetivos que suelen acompañarlos (en exclusiva, selectiva, autorizada, directa, indirecta, simple...).

Esta confusión terminológica se hace aún más patente en el ámbito europeo, dado que no existe una regulación uniforme de estos contratos en la UE, contrariamente a lo que ocurre con otros contratos, como el de agencia. La distribución comercial solamente se regula indirectamente o de forma tangencial a nivel europeo a través del Derecho de la competencia (Manzanares, 2008). No obstante, esta regulación no es inclusiva de todos los contratos de distribución, sino que ignora todos aquellos acuerdos que se consideran inocuos para la libre competencia en el mercado interior.

La aclaración de estos conceptos a nivel europeo es muy necesaria, al menos desde el punto de vista del Derecho internacional privado europeo (en adelante, "EPIL", European Private International Law). La existencia de conceptos claros y autónomos de estos contratos facilitaría a los tribunales de los Estados Miembros que aplican EPIL la labor de calificación, tanto en sede de competencia judicial internacional como de Ley aplicable, y además otorgaría seguridad jurídica a los contratantes.

Para poder construir un concepto autónomo de contrato de distribución o concesión de venta a nivel europeo (que sea válido, al menos, para EPIL), se ha de partir de un análisis comparativo del Derecho de los Estados Miembros, así como de la finalidad que persigue el mismo (STJUE de 19 de diciembre de 2013, Corman-Collins SA v. La Maison du Whisky SA, as. C-9/12, EU:C:2013:860, párrafos 27 y 28).

\section{Análisis de Derecho comparado}

Si se comienza por el análisis comparativo, en los Estados Miembros se puede establecer una distinción en función del tratamiento que se da a los distribuidores o concesionarios entre los países de civil law, en que se les distingue claramente de otros intermediarios comerciales, e incluso entre ambas figuras, y los países de common law, en que se ha desarrollado un concepto más unitario de "intermediario comercial" o "agente", que puede incluir también a los distribuidores y a los concesionarios de venta (Crahay, 1991:3).

De todos los Estados Miembros, tan sólo Bélgica posee una normativa específica en relación a los contratos de distribución, la Ley de 27 de julio de 1961 relativa a la resolución unilateral de contratos de concesión de venta en exclusiva con duración indefinida ( $M B 21$ abril 1971). En el resto de países europeos la doctrina y la jurisprudencia quienes han elaborado el concepto y características de estos contratos, igualándolos o estableciendo alguna diferencia entre distribuidor y concesionario (Guardiola Sacarrera, 1998:105).

La mencionada Ley belga define los contratos de concesión de venta como "cualquier acuerdo en virtud del cual un concedente atribuye a uno o a varios concesionarios el derecho a vender, en su propio nombre y por cuenta propia, los productos que el concedente fabrica o distribuye". Tanto en este país como en Francia, donde sólo se contemplan algunos aspectos de estos contratos, como la regulación del pacto de exclusiva, en la Ley de 14 de octubre de 1943 (JO 14 octubre 1993) este concepto es totalmente equivalente al de "contrato de distribución" (Crahay, 1991:2; Maseda, 2000:198). 
En Italia y España, en cambio, ambos conceptos no son equivalentes, sino que existe entre ellos una relación de género (distribución) y especie (concesión de venta). En Italia, en que los contratos de distribución se regulan por indicación jurisprudencial por las reglas del art. 1569 del Código Civil sobre contratos de suministro, esta distinción se basa en la existencia de algún tipo de privilegio territorial del concedente respecto al distribuidor (Fiore, 2003). En España, en que los contratos de distribución carecen actualmente de regulación específica (existían disposiciones relativas a los contratos de distribución de vehículos a motor en la disposición adicional primera de la Ley 2/1992, de 27 de marzo, sobre Contrato de Agencia, pero su aplicación se suspendió por la Disposición Final Cuarta de la Ley 7/2011, de 11 de abril), esta distinción se incluyó en el actualmente abandonado Proyecto de Ley 122/000008 de Contratos de Distribución (BOCG, serie B, núm. 8-1, de 27 diciembre 2011). Este proyecto de Ley define el contrato de concesión comercial como un contrato de distribución en exclusiva (art. 2). Este texto no ha recogido la postura de la doctrina española, para la que la especialidad de los contratos de concesión frente a los de distribución radica en el destinatario de los productos que revende el distribuidor: cuando los productos a comercializar vayan dirigidos directamente a los consumidores finales de los mismos se estaría ante un contrato de concesión (Pellisé de Urquiza, 1999:22). Desde otro punto de vista, el contrato de concesión sería el contrato en el que el distribuidor se encuentra en el último eslabón de la cadena de comercialización del producto (Hesselink et al., 2006:59).

Ante este panorama de indefinición, lo que sí se puede afirmar es que los contratos de concesión de venta se consideran en la Unión Europea, siempre y en todo caso, contratos de distribución, si bien el término se utiliza en algunos Estados Miembros como sinónimo a "distribución" y en otros para designar algunas especialidades de dichos contratos.

\section{Finalidad del contrato en la práctica comercial}

Realizado este análisis de Derecho comparado, el segundo paso sería analizar la finalidad de estos contratos en la práctica comercial europea.

Todos los contratos de distribución, incluido el de concesión en aquellos Estados Miembros en que se concibe como una especialidad del primero, se celebran con una misma finalidad, que es el establecimiento de un marco común y estable para la comercialización de los productos del empresario principal (Alonso Soto, 2007:629; Frignani, 2012). Esta finalidad, por lo tanto, no se agota con la mera transmisión de la propiedad de los bienes del empresario principal al distribuidor (Calvo Caravaca et al., 2014:729). Por ello, la jurisprudencia de los Estados Miembros no suele considerar como contratos de distribución los meros contratos de suministro o abastecimiento o los contratos de transferencia de tecnología que no impliquen la imposición de sistemas de comercialización de los productos o servicios obtenidos.

En la práctica comercial habitual, las prestaciones que se intercambian las partes de un contrato de distribución comercial, y que se estructuran alrededor de la finalidad mencionada, pueden resumirse en las siguientes:

El empresario principal se compromete a otorgar al distribuidor un derecho de comercialización de sus bienes o servicios, lo que conlleva la obligación de suministrarle los mismos, en ocasiones en exclusiva, así como la facultad de organizar ciertos aspectos accesorios de la venta final de dichos bienes o servicios, como pueden ser la estrategia de venta, publicidad, precio, ofertas, garantía, servicio postventa. El principal también puede otorgar al distribuidor un derecho de uso sobre sus logos, marcas o rótulos. 
El distribuidor, por su parte, se compromete a adquirir y revender esos bienes (en ocasiones, con un compromiso de compra mínima) o bien a comercializar esos servicios. Ello implica un compromiso de promoción de la imagen del principal y de forma adicional puede incluir la asistencia a los adquirentes de los productos o servicios. El distribuidor también se obliga a acatar las instrucciones del principal en los aspectos antes mencionados (Ruiz Peris, 2013:77; Crahay, 2001:11).

\section{COMPETENCIA JUDICIAL INTERNACIONAL EN DEFECTO DE PACTO Y CONTRATOS DE DISTRIBUCIÓN EN EL REGLAMENTO BRUSELAS I BIS}

Como ya se indicó por la autora en un trabajo previo, los contratos de distribución internacional que se formalizan por escrito suelen incluir una cláusula atributiva de competencia o jurisdiction clause (Cebrián Salvat, 2013: 126).

No obstante, una cantidad bastante significativa de estos contratos se perfecciona verbalmente (por el simple concurso entre oferta y aceptación en ferias, muestras o exhibiciones, reuniones, conversaciones telefónicas) o incluso por escrito pero sin que se llegue a la suscripción de un documento ad hoc (por ejemplo, mediante el intercambio de emails). Esta falta de formalización por escrito de los contratos de distribución es mucho más prolífera que la de otros contratos internacionales. Esto se debe a que los acuerdos de distribución son instrumentos con los que los empresarios se encuentran muy familiarizados, ya que constituyen la manera más fácil que tienen éstos de internacionalizar una red comercial: a través de un contrato de distribución, el empresario asume un coste y un riesgo mucho menor que el que conllevaría su establecimiento en un nuevo mercado por sus propios medios, en un contexto económica y jurídicamente desconocido para él. Este fenómeno se acrecienta aún más en el ámbito europeo, gracias a la creación del mercado único y la inexistencia de "fronteras" (cross-border implications) como consecuencia del reconocimiento de la libre circulación de personas, bienes, servicios y capitales del Tratado de la Unión Europea, que aumentó la confianza de los operadores y por lo tanto las relaciones comerciales entre ellos (Cebrián Salvat, 2013: 126).

Debido a estas circunstancias, cuando surge un litigio relativo a un contrato de distribución o de concesión de venta internacional al que le es de aplicación el Reglamento Bruselas I bis (Reglamento 1215/2012 del Parlamento europeo y del Consejo de 12 de diciembre de 2012 relativo a la competencia judicial, el reconocimiento y la ejecución de resoluciones judiciales en materia civil y mercantil -refundición-, DOUE L 351/1, 20 diciembre 2012), los tribunales de los Estados Miembros han de aplicar en muchas ocasiones las normas en defecto de pacto de sumisión de dicho instrumento.

Los foros que permitirán a los tribunales de dicho Estado declararse competentes para conocer de un caso derivado de un contrato de distribución o de concesión de venta son, a elección del demandante, (i) el foro general del domicilio del demandado (art. 4 RB-I bis) y (ii) el foro especial en materia contractual (art. 7.1 RB-I bis). La elección de uno u otro foro por parte del actor se puede fundamentar en muy diversas razones, tanto procesales (vinculación fáctica con el objeto del proceso, lugar en que han de practicarse las pruebas, o donde podrá ejecutarse posteriormente la sentencia) como sustantivas (voluntad de sujetar al deudor a los órganos jurisdiccionales del lugar donde debe cumplir su obligación) (Fernández Rozas et al., 2009:479). 


\section{A. El foro general del domicilio del demandado}

En virtud del mismo, los tribunales de un Estado miembro serán competentes para conocer de un litigio surgido de un contrato de distribución cuando el demandado tuviere su domicilio en dicho Estado miembro (art. 4 RB-I bis).

En relación a su aplicación a los contratos de distribución se han de señalar que el mismo presenta una ventaja sustancial frente al foro especial en materia contractual, y es que se extiende tanto la materia contractual como extracontractual. De este modo, el foro del domicilio del demandado atribuye competencia también en caso en que el objeto de la reclamación no sea considerado como directamente derivado del contrato (reclamaciones interpuestas por terceros perjudicados por el contrato, así como casos de boicot o violación de las reglas sobre competencia desleal, reclamaciones derivadas de relaciones precontractuales...), lo que da seguridad al demandante de la admisión a trámite de su demanda (Calvo Caravaca et al., 2014a:229; Rémy-Corlay, 2003:53).

\section{B. El foro especial en materia contractual.}

El art. 7.1 del Reglamento Bruselas I bis abre un foro especial para materia contractual alternativo al foro del domicilio del demandado. Este artículo, al igual que su antecesor el art. 5.1 del Reglamento Bruselas I, recoge distintas opciones para determinar el tribunal competente, en función de la calificación que se otorgue a cada contrato internacional: (i) si el contrato se califica como una compraventa internacional de mercaderías, serán competentes los tribunales del lugar del Estado Miembro en que, según el contrato, hayan sido o deban ser entregadas las mercaderías (art. 7.1.b, inciso primero RB-I bis); (ii) si el contrato se califica como una prestación de servicios, serán competentes los tribunales del lugar del Estado Miembro en que, según el contrato, hayan sido o deban ser prestados los servicios (art. 7.1.b, inciso segundo RB-I bis); (iii) en caso de que el contrato no se considere una compraventa de mercaderías o una prestación de servicios, o se excluya expresamente por las partes la aplicación de la letra $\mathrm{b}$ del precepto, serán competentes los tribunales del lugar del Estado Miembro en el que se haya cumplido o deba cumplirse la obligación que sirva de base a la demanda (art. 7.1.a RB-I bis).

El establecimiento de esta regla especial para los contratos de compraventa de mercaderías y de prestación de servicios fue la solución adoptada por el Reglamento Bruselas I a los problemas planteados por la configuración anterior de este foro en el Convenio de Bruselas de 27 de septiembre de 1968, antecedente al citado Reglamento, que obligaba a identificar en todo caso la obligación litigiosa (STJCE 6 octubre 1976, as. 14/76, De Bloos vs. Bouyer, EU:C:1976:134). La simplificación operada por esta modificación es considerable y bienvenida, de forma que, en los casos encuadrables en esta regla especial, ya no será necesario aislar dicha obligación objeto del litigio, pero la misma suscita una nuevo tipo de dificultades: las dificultades de calificación (Gaudemet-Tallon, 2002:147; Huet, 2010:146).

Estas dificultades de calificación se muestran con todo su esplendor en los contratos de distribución y de concesión de venta que como ya se ha indicado carecen de una regulación uniforme a nivel europeo. Hasta el momento, y a falta de un pronunciamiento expreso del TJUE al respecto, la doctrina había planteado las alternativas que se exponen resumidamente a continuación (con más detalle, Cebrián Salvat, 2013:130).

a. La calificación del contrato de distribución caso por caso

Este resultado es consecuencia de que el criterio propuesto por los autores para calificar un contrato a efectos del art. 7.1 RB-I bis es el "centro de gravedad", "obligación principal" o 
“elemento dominante" (Garcimartín, 2010:229; Forner Delaygua, 2009:311; Mankowski, 2007:132). Este criterio es el que parecía haber escogido el TJUE en el caso Car Trim (STJUE 25 febrero 2010, Car Trim, as. c-381/08, EU:C:2010:90, apartados 31 y 32). De esta forma, los contratos de distribución o de concesión de venta se considerarán como compraventa de mercaderías o prestación de servicios según el caso concreto, ya que ese elemento principal puede variar en función del peso que le den las partes en un contrato concreto (Garcimartín, 2012:90; Sent. Cour Cass. Francia 5 marzo 2008, 23 de enero 2007, 27 marzo 2007, 14 noviembre 2007). La balanza se inclinaría a favor de un tipo u otro en función del "grado y cantidad" de actividades que el contrato atribuye al distribuidor (Mankowski, 2007:133).

b. Una calificación única para todos los contratos de distribución: el contrato de distribución como contrato de prestación de servicios

La opción alternativa a la anterior es la de elegir un criterio que no haga variar la calificación del contrato caso por caso. El criterio que se ha propuesto para ello es el de la finalidad económica del contrato (Berlioz, 2008:675; Calvo Caravaca, 2014b:732; Jacquet, 2008:521). Todo contrato que se considere encuadrado dentro de una categoría contractual tendrá la misma finalidad económica, y por lo tanto una misma calificación a efectos del art. 7.1 RB-I bis. Así, un contrato sería calificado como "prestación de servicios si su finalidad económica es "llevar a cabo una actividad a cambio de una remuneración" (STJUE 23 abril 2009, Falco Privatstiftung y Rabitsch, as. c-533/07, EU:C:2009:257, apartado 29); como "compraventa de mercaderías" si su finalidad es "la transmisión de la propiedad de unos determinados productos de una parte a la otra" (STJUE Car Trim, antes citada, apartado 32), y como ninguno de los anteriores, cuando se considere que el contrato tiene una finalidad distinta.

Como se indicó al comienzo de este trabajo, la finalidad económica de contrato de distribución o concesión de venta es la comercialización de los productos del principal por parte del distribuidor o concesionario. La mayoría de los autores que han tomado partido por este criterio de calificación se han inclinado por determinar que esta finalidad económica es una "prestación de servicios" por parte del distribuidor al concedente (Calvo Caravaca et. al., 2014:732; Cebrián Salvat, 2013: 134; Gaudemet-Tallon, 2002:147; Jacquet, 2008:521; Lupoi, 2011: 92; Rodríguez Rodrigo, 2014). En consecuencia, los tribunales competentes tenían que ser los tribunales del lugar del Estado Miembro en que dichos servicios fueran prestados, es decir, el lugar del Estado Miembro en que el distribuidor llevara a cabo la comercialización de los productos.

Esta calificación parecía la más acorde con una interpretación sistemática del EPIL, si se tenía en cuenta el considerando 17 del Reglamento Roma I (Reglamento (CE) 593/2008 del Parlamento Europeo y del Consejo de 17 junio 2008 sobre la ley aplicable a las obligaciones contractuales -Roma I-, DOUE L 177/6 4 julio 2008). Aun así, la doctrina no veía en este considerando una muestra concluyente (Garcimartín, 2010:230, "tampoco se le puede conceder mucha importancia a esa calificación pues en el considerando 17 afirma que los contratos de distribución son "contratos de servicios" sujetos a normas específicas, y sin embargo, en el articulado, establece la misma solución que para los demás contratos de servicios si consideramos, como parece lo lógico, que el distribuidor es quien presta el servicio (vid. Art. 4.1 (b) y (f)"). 


\section{EL CONTRATO DE CONCESIÓN DE VENTA EN EL ART. 7.1 DEL REGLAMENTO BRUSELAS I BIS 1: NUEVAS REFLEXIONES A PARTIR DE LA STJUE CORMAN-COLLINS V. LA MAISON DU WHISKY}

Así las cosas, se planteó una cuestión prejudicial al TJUE en 2012 en relación a lo que el juez de instancia denominó "contrato de concesión de venta" y su calificación a efectos del art. 5.1 RB-I (actual art. 7.1 RB-I bis). El TJUE emitió su sentencia el 19 de diciembre de 2013 (STJUE Corman-Collins SA v. La Maison du Whisky SA, ya mencionada).

Los hechos del caso fueron los siguientes: La Maison du Whisky, una corporación con sede en Francia, tenía una relación comercial con una empresa belga, Corman-Collins, que consistía en la compra por parte de Corman-Collins de varias marcas de whisky de la empresa francesa para su reventa en Bélgica. Sin previo aviso, La Maison du Whisky informó a Corman-Collins de que conferiría la distribución exclusiva de sus marcas a otra empresa, a través del cual se invitó a Corman-Collins a hacer sus pedidos.

Corman-Collins demandó a La Maison du Whisky ante los tribunales belgas. Solicitaba una indemnización en virtud de la legislación belga. La empresa demandada alegó la incompetencia de dichos tribunales en virtud del Reglamento Bruselas I, y la demandante respondió invocando una norma belga de producción interna que otorga a los tribunales belgas competencia con respecto a ciertos contratos de distribución, establecida en el art. 4 de la Ley belga de 27 de julio 1961. Además, las partes estaban en desacuerdo en cuanto a la naturaleza jurídica de su relación comercial. Corman-Collins sostenía que el contrato era un acuerdo de distribución exclusiva, mientras que La Maison du Whisky afirmaba que se trataba de un contrato de venta de mercaderías.

El tribunal que conocía del asunto tenía dudas respecto a ambas cuestiones. En consecuencia, dicho tribunal solicitó al TJUE que se pronunciara, en primer lugar, acerca de la posibilidad de basar su competencia en la Ley belga de 27 de julio de 1961, aun cuando, en opinión del tribunal, el Reglamento Bruselas I era aplicable al caso tanto ratione loci como ratione materiae. En segundo lugar, el tribunal preguntó si, en el caso de que el Reglamento Bruselas I fuera aplicable, un contrato como el controvertido en el caso se debe considerar como una venta de mercaderías, como una prestación de servicios o como ninguno de ellos.

En cuanto a la primera cuestión, el TJUE respondió que estaba excluida la aplicación de dicha norma nacional de competencia, ya que el caso estaba comprendido en el ámbito de aplicación del Reglamento Bruselas I. Según el Tribunal, las reglas comunes sobre competencia judicial internacional que recoge en el Reglamento deberían en principio aplicarse y prevalecen sobre las normas de competencia vigentes en los diferentes Estados miembros (Cebrián Salvat, 2015:117).

En cuanto al segundo bloque de preguntas, la Corte respondió que el artículo 5.1.b RB-I, segundo apartado, relativo a los contratos de prestación de servicios era aplicable a un contrato de distribución en exclusiva que contenga términos específicos relativos a la distribución por el concesionario de los bienes que le son vendidos por el principal. Es decir, el TJUE consideró que estos contratos eran contratos de prestación de servicios a cargo del distribuidor a efectos del 5.1 RB-I (7.1 RB-I bis).

En relación a lo expuesto en este trabajo, de esta Sentencia del TJUE cabe destacar las reflexiones que se exponen en los apartados siguientes. 


\section{El concepto europeo de contrato de concesión de venta}

El TJUE afirma que para contestar a las cuestiones planteadas es necesario ante todo precisar el concepto de contrato de concesión, ya que se trata de un concepto no definido en el Derecho europeo y que puede responder a realidades distintas en los Estados Miembros (apartado 25). Esta forma de proceder, si bien calificada de injustificada y pretoriana por la doctrina (Heymann, 2014:896), puede resultar muy útil para los jueces nacionales que en un futuro tengan que calificar un contrato de distribución.

Para la precisión de este concepto a nivel europeo, de acuerdo con sus propios precedentes, ha recurrido a la comparación del Derecho de los Estados Miembros y al estudio de la finalidad de estos contratos. En cuanto a la finalidad del contrato, se refiere a la misma como "asegurar la distribución de los productos del concedente" (STJUE Corman Collins, ya mencionada, apartado 27). En relación al análisis comparativo, se limita a indicar que "el contrato de concesión se presenta en forma de un acuerdo marco que establece las reglas generales aplicables en el futuro a las relaciones entre el concedente y el concesionario en lo que atañe a sus obligaciones de suministro y/o abastecimiento, y prepara los contratos de venta ulteriores" (apartado 28).

Junto a las consideraciones anteriores, el TJUE parece dar una definición de este contrato de concesión de venda cuando añade que, para asegurar esa comercialización, "el concedente se compromete a vender al concesionario, al que ha seleccionado con ese fin, las mercancías que éste le encargue para satisfacer la demanda de su clientela, mientras que el concesionario se obliga a comprar las mercancías que necesite" (apartado 27 in fine).

Esta definición del TJUE no se distingue en nada del concepto de "contrato de distribución", no hay ninguna especialidad de las que se han puesto de manifiesto por parte de la doctrina española e italiana en relación a estos contratos (necesidad de pacto de exclusiva territorial, necesidad de destinar los productos a consumidores finales...). En concreto, el TJUE no cierra este contrato únicamente al caso de la distribución en exclusiva, aunque sí exige una mínima selección del distribuidor por parte del empresario principal: "el contrato de concesión descansa en una selección del concesionario por el concedente. Esta selección, aspecto característico de esa clase de contrato, confiere al concesionario una ventaja competitiva consistente en que sólo él tiene derecho a vender los productos del concedente en un territorio dado, o al menos, en que un número limitado de concesionarios disfrutará de ese derecho" (apartado 40) (contra, Bureau, 2014:667, para el que el TJUE únicamente se ha referido a la distribución en exclusiva).

En la versión española de la Sentencia, el Tribunal utiliza ambos términos, "contrato de concesión de venta" y "contrato de distribución", y lo hace de forma equivalente. Lo mismo ocurre con las versiones francesa (concession de vente y distribution) e italiana (concessione di vendita y distribuzione). Esta equivalencia se hace aún más patente en la versión inglesa de la Sentencia, que se refiere en todo momento a "contrato de distribución" (distribution contract). Lo anterior hace pensar que el TJUE considera ambos términos, "contrato de concesión de venta" y "contrato de distribución" como sinónimos, independientemente de que los mismos puedan tener significados distintos y acarrear obligaciones diferentes en algunos Estados Miembros. Se adhiere así a la postura francesa y belga que se exponía al comienzo de este trabajo, quizá de forma inconsciente, debido a que las partes del litigio son de estas nacionalidades.

De este modo, se puede afirmar que el concepto europeo de "contrato de concesión de venta" es equivalente al concepto de "contrato de distribución" y que dicho concepto es el siguiente: "acuerdo marco cuyo objeto es un compromiso de suministro y de abastecimiento concluido para el futuro entre dos operadores económicos, que contiene estipulaciones 
contractuales específicas sobre la distribución por el concesionario de las mercancías vendidas por el concedente" (apartado 36). El TJUE deja fuera de este concepto las relaciones comerciales, aunque sean duraderas, que se limitan a acuerdos sucesivos de entrega y recepción de mercancías (apartado 36): en estos casos no se estaría ante un contrato de distribución en su sentido europeo.

\section{El criterio del tribunal: "la obligación característica"}

Una vez acotado el concepto de contrato de concesión de venta a nivel europeo, el TJUE intenta encuadrar ese concepto en alguno de los apartados del art. 5.1 RB-I (art. 7 RB-I bis). Para ello, el TJUE sigue la estela de los casos Car Trim y Falco (SSTJUE ya citadas) e indica que el criterio para determinar si un contrato es una "compraventa de mercaderías", una "prestación de servicios" o ninguno de estos es el de la "obligación característica".

Parece alinearse así con la primera de las dos posturas expuestas más arriba, según la cual la calificación de un contrato a efectos de la obligación característica del contrato y no de su finalidad económica, cuestión recibida con sorpresa por parte de la doctrina, más aún cuando el TJUE utiliza en la misma sentencia ese enfoque teleológico para definir el contrato de concesión de venta (Bureau, 2014:668; Heymann, 2014:895).

Sin embargo, seguidamente el TJUE concreta tal "obligación característica", e indica que es la ejecutada por el concesionario, quien "al llevar a cabo la distribución de los productos del concedente toma parte en el desarrollo de su difusión" (apartado 38). No indica que dicha obligación característica haya de ser tenida en cuenta contrato a contrato, sino que la misma forma parte de la misma esencia del contrato de distribución. Lo que habrá que ver es si el contrato es o no un contrato de distribución en el sentido europeo, pero una vez que lo es, su "obligación característica" siempre será, a ojos del tribunal, esa comercialización de los productos del empresario principal por parte del distribuidor.

De esta forma, el TJUE parece utilizar el concepto al que la doctrina se había referido como "finalidad económica" del contrato (una finalidad común a todos los contratos de una categoría), con el nombre de "obligación característica". Intenta distinguir una especie de "obligation finale" (Bureau, 2014:668). La prueba de ello es que no fija ninguna medida para determinar que la obligación que tiene más peso en el contrato es la comercialización de los bienes por parte del distribuidor (¿en base a la longitud de las cláusulas que regulan cada una, según el orden en que se encuentran dispuestas, según la importancia económica de la obligación en el conjunto de la relación contractual?), sino que simplemente se refiere a que las partes suscriben el contrato para tal fin, del que ambas salen beneficiadas. Habla de obligación característica, pero en el fondo se fija en la finalidad del contrato tal y como la define al comienzo mismo de la Sentencia (apartado 26).

De esta forma de razonar del TJUE se pueden extraer dos consideraciones a futuro:

La primera, es que el TJUE no realiza una operación de calificación convencional: es cierto que interpreta primero los términos del art. 5.1 RB-I (compraventa de mercaderías, prestación de servicios), como en toda operación calificatoria, pero posteriormente no encaja en estos, a partir de una operación de simple lógica y observación fáctica, un contrato en concreto, sino que intenta calificar en ellos la categoría genérica definida, la de los contratos de distribución. Esto modifica la operación de calificación que tendrá que realizar en adelante el juez de instancia: solamente tendrá que calificar un contrato en concreto como contrato de distribución, a lo que automáticamente le vendrá asociada su condición de contrato de prestación de servicios a los efectos del art. 7.1 RB-I bis. Una determinación del foro caso a caso no puede ser regla sino excepción, ya que generaría gran inseguridad jurídica, y podría 
suponer que las partes se vieran sometidas a un tribunal que en un principio no podían haber previsto. Tampoco parece acorde cuando los contratos internacionales suelen ser "contratos tipo", con una forma suficientemente uniforme en la práctica comercial internacional como para que su calificación como compraventa o prestación de servicios haya de llevarse a cabo caso a caso.

La segunda, es que el TJUE parece utilizar el criterio de la "finalidad económica" del contrato, o al menos define cuál es la obligación característica del contrato en atención a dicha finalidad, de forma que este criterio de la "finalidad económica" sigue siendo válido en el futuro para determinar si un contrato ha de ser considerado como contrato de compraventa de mercaderías, de prestación de servicios, o como ninguno de ellos. Esta es la única forma de salvar, en relación a otros contratos respecto a los que el TJUE aún no se ha pronunciado, como por ejemplo el contrato de franquicia, el debate que en sede de Ley aplicable se vivió en relación a la prestación característica de ciertos contratos y que, como es sabido, tiene difícil solución (Bureau, 2014:668; Heymann, 2014:895; Carrascosa, 2005:349).

\section{El contrato de concesión de venta como contrato de prestación de servicios}

En definitiva, el TJUE apuesta por determinar que los contratos de distribución son en todo caso contratos de prestación de servicios a cargo del distribuidor a efectos del art. 5.1 RB-I (actual 7.1 RB-I bis). El Tribunal de Luxemburgo ve en la comercialización de los productos del empresario principal la "realización de la actividad" y en la ventaja competitiva que ese empresario principal proporciona al distribuidor, que puede ir acompañada de otras ayudas como el soporte a la publicidad, la transmisión de conocimientos técnicos, o las facilidades de pago, la "remuneración atribuida como contrapartida de dicha actividad", elementos ambos (actividad y remuneración) que caracterizan la definición autónoma del contrato de prestación de servicios (apartados 39 y 40) (Lupoi, 2014:302). Al afirmar que la remuneración no tiene por qué ser siempre en dinero el TJUE flexibiliza su postura en cuanto a la interpretación estricta que había afirmado en su jurisprudencia anterior que debía tener el apartado b del art. 5 RB-I (Heymann, 2014:891; caso Falco, ya mencionado).

La toma de partido por la prestación de servicios implica la exclusión de la calificación de estos contratos como compraventa de mercaderías. La STJUE descarta esta calificación al indicar que la "obligación característica" (finalidad económica) de la compraventa de mercaderías es la entrega y la recepción de las mercancías (apartados 35 y 36), es decir, la transmisión de su propiedad. Esta finalidad no casa con la de un contrato de distribución, que es un "acuerdo marco", y ello independientemente de que pueda dar lugar a distintas operaciones de venta sucesivas. En cualquier caso queda sin aclarar la cuestión de qué Ley se ha de aplicar a un litigio que surja de una de esas operaciones de venta enmarcadas en el contrato de distribución, si bien se ha indicado que en la decisión parece entreverse la voluntad del TJUE de considerar esas operaciones de compraventa como contratos independientes del contrato marco de distribución (Espiniella Menéndez, 2014:241).

La toma de partido por la prestación de servicios supone también descartar que el contrato de distribución pueda quedar fuera de la letra $b$ del art. 5.1 RB-I o 7 RB-I bis y regirse por lo tanto por la letra a de los citados preceptos, y ello a pesar de que en los contratos de distribución se produzcan en ocasiones cesiones de derechos incorporales (contratos que el TJUE ha calificado en la Sentencia Falco, ya citada, como sujetos a la letra a de estos preceptos). La STJUE no llega a plantearse esta cuestión puesto que la regla de la letra $b$ es especial frente a la del apartado a, que además a partir de esta decisión parece tener un carácter residual (Heymann, 2014: 897). 
Esta calificación del contrato de distribución o de concesión de venta como contrato de prestación de servicios parece la opción no sólo más acorde con la finalidad económica del contrato, sino también más beneficiosa para las partes y el comercio internacional. Como se indicó en el trabajo del que este trae causa, considerar el contrato de distribución como un contrato de prestación de servicios es además la interpretación más acorde con el tratamiento en cierto modo protector que el Reglamento Roma I hace del distribuidor (Cebrián Salvat, 2013:136). Cuando dicho distribuidor sea el demandante, el art. 5.1 RB-I (art. 7.1 RB-I bis) en la mayoría de ocasiones conducirá a los tribunales de un Estado distinto de los del domicilio del empresario principal, proporcionándole un "foro de ataque" en el lugar en el que dicho distribuidor preste sus servicios, que en la mayoría de los casos será en el Estado de su domicilio, dado que los proveedores suelen elegir distribuidores afincados en el mercado a conquistar, que tengan un mayor conocimiento del funcionamiento de dicho mercado.

Este efecto se consigue además sin desfavorecer al empresario principal de manera excesiva, puesto que se trata de un foro que tanto éste como el distribuidor pudieron prever (el del lugar en que se distribuyen los productos), por mucho que, cuando el demandante sea el empresario principal, este foro quedará la mayoría de las veces inhabilitado: el domicilio del demandado suele coincidir con el lugar de ejecución de la obligación. En los casos en que no sea así (caso, por ejemplo, de un distribuidor afincado en un país de Europa del Este que se dedique a distribuir a toda la zona), le permitirá abrir una alternativa permitiéndole demandar no sólo en el lugar en que dicho distribuidor esté domiciliado sino también donde se produzca la distribución de los productos que haya dado lugar a la controversia.

\section{CONSIDERACIONES FINALES}

Primera. Los contratos de distribución internacional han sido el paradigma de contrato complejo utilizado por los autores para estudiar la cuestión de la determinación de la competencia judicial internacional en defecto de pacto en el anterior Reglamento Bruselas I y actual Reglamento Bruselas I bis.

Segunda. Algunas de las incertidumbres que existían hasta el momento en relación a estos contratos han sido despejadas por el TJUE en su Sentencia de 19 de diciembre de 2013, Corman-Collins SA v. La Maison du Whisky SA. La primera de éstas ha sido la de proporcionar un concepto europeo de contratos de distribución, que el TJUE ha equiparado al término "contrato de concesión de venta", siguiendo la corriente francesa y belga.

Tercera. La siguiente incertidumbre despejada ha sido la de su calificación a efectos del art. 5 RB-I (actual art. 7 RB-I bis). Como recomendaba parte de la doctrina, el TJUE se ha decantado por calificar la categoría contractual de los contratos de distribución o concesión de venta como contratos de prestación de servicios a efectos del citado artículo. Para efectuar dicha calificación ha utilizado como criterio el de la búsqueda de la finalidad económica de estos contratos, que es la comercialización de los productos del empresario principal por parte del distribuidor, si bien se ha referido a dicha finalidad como "obligación característica" del contrato, de forma que se podría hablar del criterio de la "obligación final", es decir, la obligación del contrato que refleja esa finalidad económica.

Cuarta. En consecuencia de lo anterior, serán competentes para conocer de un litigio derivado de un contrato de distribución los tribunales del lugar del Estado miembro en el que hubieren sido o debieren ser prestados los servicios de distribución, es decir, donde se 
comercializaron o debieron de comercializarse los productos distribuidos. Esta solución es la que da al foro un sentido más acorde al tratamiento de favor que recibe el distribuidor en materia de Ley aplicable, sin perjudicar al empresario principal.

Quinta. El TJUE sigue en la línea que ha marcado su propia jurisprudencia, y que opta por calificar las categorías contractuales "en abstracto". Adopta una solución válida para cada "tipo" contractual, de forma que no habría que estar al caso concreto para determinar el tipo de contrato. Esto genera una mayor seguridad jurídica, porque permite a las partes una mayor previsibilidad del foro al que pueda verse sometida su controversia y se alinea con la solución de primer grado para fijar directamente la Ley aplicable a los contratos en el art. 4.1 del Reglamento de Roma I, establecida partiendo de la consideración de que la teoría del caso concreto es siempre complicada y ralentiza la fijación tanto del tribunal competente, como de la Ley aplicable.

Sexta. En el fondo, se pone de manifiesto la actitud que el TJUE toma cuando decide sobre una cuestión prejudicial, en virtud de la cual no decide únicamente para las partes, es decir, no pretende calificar la relación jurídica concreta que le plantea el juez de instancia, sino que decide de cara a todo el mercado interior. Esto supone crear unas normas de competencia que tienden a la creación de categorías normativas, incluso más allá de los preceptos que las contienen. En este intento, el TJUE se desdice incluso de su jurisprudencia anterior e intenta evitar que la mayoría de los casos posibles caigan en la indefinición del apartado a del art. 5.1 RB-I, art. 7.1 RB-I bis. Es la clara apuesta del TJUE por un EPIL que crea seguridad jurídica y certeza legal en las transacciones de los ciudadanos europeos, un EPIL al servicio del mercado interior.

\section{BIBLIOGRAFÍA}

ALONSO SOTO, R. (2007). "Contratos de colaboración empresarial". En A. Menéndez (dir.). Lecciones de Derecho Mercantil. Pamplona: Thomson Civitas, pp. 603-626.

- (2013). "Bases para una futura regulación de los contratos de distribución". En A. J. Viera González, J. A. Echebarría Sáenz y J. I. Ruiz Peris (dirs.). La reforma de los contratos de distribución comercial. Madrid: La Ley, pp. 54-65.

BERLIOZ, P. (2008). "La notion de fourniture de services au sens de l'article 5-1 b) du règlement Bruxelles I", JDI Clunet: 675-717.

BUREAU, D. (2014). "Note à Cour de justice de l'Union européenne -19 décembre 2013- aff. C-9/12", Rev. Crit. DIP., 103 (3): 660-669.

CALVO CARAVACA, A. L. y J. CARRASCOSA GONZÁLEZ, J. (2014a). Derecho Internacional Privado (Volumen I), Granada: Comares.

- (2014b). Derecho Internacional Privado (Volumen II), Granada, Editorial Comares, 2014.

CARRASCOSA GONZÁLEZ, J. (2005). "La lucha por la prestación característica (I): Los contratos internacionales de distribución". En A. L. Calvo Caravaca y S. Areal Ludeña (dirs.). Cuestiones actuales del Derecho Mercantil Internacional. Madrid: Colex, pp. 349-370.

CEBRIÁN SALVAT, M A. (2013). "Competencia judicial internacional en defecto de pacto en los contratos de distribución europeos: el contrato de distribución como contrato de prestación de servicios en el Reglamento 44", CDT, 5(1):125-138.

- (2015). "Agency and distribution contracts: national rules v. European private international law" en J.

S. Bergé, M. Gardeñes y S. Franq (coords.) Boundaries of European Private International Law. Bruselas: Bruylant Larcier, pp. 117-132.

CRAHAY, P. (1991). Les contrats internationaux d'agence et de concession de vente. Paris: LGDJ.

DURÁN AYAGO, A. (2006). "Contratos de distribución internacional” En A. L. Calvo Caravaca y J. Carrascosa González. Curso de contratación internacional, Colex, Madrid, 2006, pp. 333-361. 
ESPINIELLA MENÉNDEZ, A. (2013). "Las operaciones de compraventa en la distribución comercial internacional", AEDIPr, 13: 423-455.

- (2014), "Sentencia del Tribunal de Justicia (Sala Primera) de 19 de diciembre de 2013, asunto C-9/12, Corman-Collins c. La Maison du Whisky", REDI, 64 (2): 239-243.

FERNÁNDEZ ROZAS, J.C. y SÁNCHEZ LORENZO, S. (2009). Derecho Internacional Privado. Pamplona: Thomson Reuters.

BOSCH CAPDEVILA, E. (2009). Derecho contractual europeo. Barcelona: Bosch. 2009.

FIORE, F. (2003). "Il contratto di concessione di vendita" Diritto\&Diritti. En: http://www.diritto.it/ articoli/commerciale/fiore.html (consultado 01/03/2015).

FRIGNANI, A. (2012). Il contratto di franchising. Orientamenti giurisprudenziali prima e dopo la legge 129 del 2004. Milano: Giuffré.

GARCIMARTÍN ALFÉREZ, F. J. (2010). "Contratos de distribución internacional: competencia judicial y Ley aplicable” En A. Alonso Ureba y otros (dirs.). Los contratos de distribución. Madrid: La Ley, pp. 221-240.

- (2012). Derecho Internacional Privado. Pamplona: Thomson Reuters.

GUARDIOLA SACARRERA, E. (1998). Contratos de colaboración en el comercio internacional. Valencia: Bosch.

HESSELINK, M.W. et al. (2006). Principles of European Law. Munich: European Law Publishers.

HEYMANN, J. (2014). "Commentaire CJUE 1ere ch. Aff. C-9/12 Corman-Collins SA c/ La Maison du Whisky SA", JDI, 2014(3): 883-889.

JACQUET, J. M. (2008). "Note aux Sents. Cour Cass. France 23 janvier 2007, 27 mars 2007, 14 novembre 2007, 5 mars 2008", JDI Clunet, pp. 521-531.

JUÁREZ PÉREZ, P. (2003). “Contratos internacionales de distribución”. En A. L. Calvo Caravaca y J. Carrascosa González. Curso de contratación internacional. Madrid: Colex, pp. 333-361.

LÓPEZ RODRÍGUEZ, A.M. (2014). "El contrato de distribución exclusiva o concesión comercial como contrato de prestación de servicios a efectos de la aplicación del foro conflictual del Reglamento Bruselas I, Comentario a la STJ de 19 diciembre de 2013". La Ley Unión Europea, 13: pp. 37-44.

LUPOI, M. A. (2014). “A Report of Recent ECJ Cases on Regulation (EU) No. 44/2001”, IJPL, (4), com. 2: 289-336.

MANKOWSKI, P. (2007). “Art. 5 Brussels I Regulation”. En U. Magnus y P. Mankowski (eds.). Brussels I Regulation. Munich: Sellier European Law Publishers, pp. 88-294.

MANZANARES, B. (2008). "Aspectos básicos del contrato de distribución internacional”. Noticias jurídicas. En: http://noticias.juridicas.com/articulos/50-Derecho-Mercantil/200811-2963145785236. html (consultado 01/03/2015).

MASEDA RODRÍGUEZ, J. (2000). Aspectos internacionales de la concesión mercantil. Santiago de Compostela: Universidade de Santiago de Compostela.

MIROSA MARTíNEZ, P. (2009). "Prólogo". En J. Fontcuberta Llanes. El contrato de distribución de bienes de consumo y la llamada indemnización por clientela. Madrid: Marcial Pons, pp. 5-12.

PELLISÉ DE URQUIZA, C. (1999). Los contratos de distribución comercial. Barcelona: Bosch.

REMY-CORLAY, P. (2003). Les concepts contractuels français à l'heure des Principes du Droit européen des contrats. Paris: Dalloz, Themes et Commentaires.

RODRÍGUEZ RODRIGO, J. (2014). Contratos internacionales de distribución comercial en el Derecho internacional privado de la Unión Europea. Granada: Comares.

RUIZ PERIS, J. I. (2013). "Las redes empresariales en el proyecto de ley de contratos de distribución español de 2011”. En A. J. Viera González, J. A. Echebarría Sáenz y J. I. Ruiz Peris (dirs.) La reforma de los contratos de distribución comercial. Madrid: La Ley, pp. 77 a 87.

VICENT CHULIÁ, F. (2003). Introducción al Derecho Mercantil. Valencia: Tirant lo Blanch. 


\section{Breve currículo:}

\section{María Asunción Cebrián Salvat}

Licenciada en Derecho (premio extraordinario fin de carrera) y en Ciencias Políticas y de la Administración. Máster en Derecho empresarial (Harvard Law School y Centro de Estudios Garrigues) y Máster Oficial en Investigación Avanzada y Especializada en Derecho (UMU). Investigadora predoctoral en el Área de Derecho Internacional Privado de la Universidad de Murcia desde febrero de 2013 (beca de la Agencia de Ciencia y Tecnología de la Región de Murcia). Comunicante en congresos de ámbito internacional ("Lès frontieres du Droit International Privée", Cátedra Jean Monnet, Universidad de Toulouse). Publicaciones en revistas de impacto internacional y en editoriales de prestigio nacional e internacional. 